\title{
TEOR DE ÓLEO EM CULTIVARES DE SOJA VISANDO A PRODUÇÃO DE BIOCOMBUSTÍVEL NO ESTADO DO TOCANTINS
}

Behavior of soybean cultivares, regarding the oil content, aiming at the production of biofuel in the state of Tocantins

Comportamiento de los cultivares de soja, en relación con el contenido de aceite con el objetivo de producer biocombustibles en el estado do Tocantins

Susane Maciel de Souza ${ }^{1}$, Rômulo Alves Morais*2,3 , Larissa da Silva Gualberto ${ }^{2,3}$, Hermanny Matos Silva Sousa ${ }^{2,3}$, Glêndara Aparecida de Souza Martins ${ }^{2}$, Joênes Mucci Peluzio ${ }^{1}$

${ }^{1}$ Laboratório de Pesquisa Agropecuárias (LPA) - Universidade Federal do Tocantins

${ }^{2}$ Laboratório de Cinética e Modelagem de Processos (LaCiMP) - Universidade Federal do Tocantins

${ }^{3}$ Programa de Pós-Graduação em Ciência e Tecnologia de Alimentos (PPGCTA -UFT) - Universidade Federal do Tocantins

*Correspondência: Laboratório de Cinética e Modelagem de Processos, Escola de Engenharia de Alimentos, Universidade Federal do Tocantins, Quadra 109 Norte, Avenida NS 15, ALCNO-14, Plano Diretor Norte, PalmasTO, CEP: 77001-090.e-mail: romuloitallo2505@gmail.com

\section{Artigo recebido em 19/02/2020 aprovado em 27/03/2020 publicado em 31/03/2020.}

\section{RESUMO}

A soja é uma importante oleaginosa cultivada em vários territórios do mundo, isto devido ao seu alto teor de lipídios e proteína contidos nos grãos, o que faz da mesma ser muito utilizada na indústria de alimentos e de biocombustível. Sendo assim este trabalho teve como objetivo identificar cultivares de soja com alto teor de óleo nas diferentes épocas de plantio no Estado do Tocantins no período de 2014/2015. Os ensaios foram conduzidos na Estação Experimental do Campus da UFT na cidade de Palmas-TO. O delineamento experimental adotado foi o de blocos casualizados, sendo cinco genótipos com três repetições em cada uma nas duas épocas de semeadura. A determinação do percentual de óleo foi realizada pelo método Soxhlet. As cultivares que apresentaram maior teor de óleo foi RAÇA $(22,49 \%)$ e STS820 (21,53\%). Na segunda época não houve diferença estatística entre as cultivares.

Palavras-chave: Blocos, produtividade, composição.

\section{ABSTRACT}

Soybean is an important oilseed crop grown in various parts of the world, due to its high content of lipids and protein contained in grains, which makes it very used in the food and biofuel industry. The objective of this work was to identify soybean cultivars with high oil content at different planting times in the State of Tocantins in the period 2014/2015. The tests were conducted at the UFT Campus Experimental Station in the city of Palmas-TO. The experimental design was randomized blocks, with five genotypes with three replicates in each of the two sowing seasons. The percentage of oil was determined by the Soxhlet method. The cultivars that presented the highest oil content were RAÇA (22.49\%) and STS820 (21.53\%). In the second period there was no statistical difference between the cultivars.

Keywords: Blocks, productivity, composition. 


\section{RESUMEN}

La soja es una semilla oleaginosa importante que se cultiva en varios territorios del mundo, debido a su alto contenido de lípidos y proteínas contenidos en los granos, por lo que es ampliamente utilizada en la industria alimentaria y de biocombustibles. Por lo tanto, este trabajo tuvo como objetivo identificar cultivares de soja con alto contenido de aceite en diferentes estaciones de siembra en el estado de Tocantins en 2014/2015. Las pruebas se realizaron en la Estación Experimental del Campus UFT en Palmas-TO. El diseño experimental fue un diseño de bloques al azar, cinco genotipos con tres repeticiones en cada uno en las dos fechas de siembra. La determinación del porcentaje de aceite se realizó mediante el método Soxhlet. Los cultivares con el mayor contenido de aceite fueron RAÇA (22.49\%) y STS820 (21.53\%). En la segunda temporada no hubo diferencia estadística entre los cultivares.

Descriptores: Bloques, productividad, composición.

\section{INTRODUÇÃO}

Com o problema do aquecimento global, cada vez mais, se torna necessário à produção de combustíveis vindos de fontes renováveis (CARVALHO et al., 2014). O Biodiesel vem se consolidando como novo negócio para a agricultura brasileira e será um importante instrumento de geração de renda no campo.

Nesse contexto de aquecimento global, a soja faz parte do conjunto de atividades agrícolas com maior destaque no mercado mundial. Nota-se que os grãos de soja tem sido o quarto grão mais consumido e produzido mundialmente, atrás de milho, trigo e arroz, além de ser a principal oleaginosa cultivada anualmente no mundo (EMBRAPA, 2013), tais dados podem ser evidenciados no mercado interno brasileiro entre as safras de 2000/01 e 2013/14, enquanto a área cultivada cresceu $49,8 \%$, a produção foi ampliada em 61,5\% (HIRAKURI; LAZZAROTTO, 2014).

A soja (Glycine $\max (L$.$) Merril), apontada$ como uma das mais importantes leguminosas, originada de clima temperado, dispõe de ampla adaptação aos climas subtropicais e tropicais. Avaliando sua composição proximal o grão de soja pode variar em torno de $20 \%$ para lipídeos, $38 \%$ para proteína e $34 \%$ para carboidratos, além de fibras e constituintes inorgânicos (EMBRAPA, 2013). Essa composição varia conforme a genética e as condições ambientais, ocasionando variações no rendimento industrial (SBARDELOTTOI et al., 2008).

Dentro do planejamento do governo de ampliar a produção de biodiesel, a soja representa a principal fonte de matéria prima, uma vez que possui cadeia produtiva estruturada e domínio tecnológico capaz de atender parte da crescente demanda por combustíveis renováveis além de diminuir a dependência dos derivados de petróleo, abrindo um novo mercado para essa oleaginosa (CAVALCANTE et al., 2011).

O cultivo de plantas oleaginosas, no Estado do Tocantins, tem aumentado nos últimos anos, em virtude da abundância de recursos hídricos, condições edafoclimáticas favoráveis, localização estratégica da BR 153, implantação da Ferrovia Norte-Sul e da Hidrovia Tocantins-Araguaia (DIAS et al., 2011). Entretanto, escassos são os trabalhos envolvendo o comportamento de cultivares de soja, para fins de biodiesel, no estado.

O presente estudo envolvendo cultivares de soja teve como objetivo identificar cultivares de com alto teor de óleo nas diferentes épocas de plantio no Estado do Tocantins no período de 2014/2015.

\section{MATERIAIS E MÉTODOS}

No período agrícola das safras 2014/2015 foram realizados dois ensaios de competição de genótipos de soja, sendo semeadas na Estação 
Experimental do Campus de Palmas da Universidade Federal do Tocantins (216 m de altitude, $10^{\circ} 10^{\prime} \mathrm{S}$ e $48^{\circ} 21^{\prime} \mathrm{W}$ ), em uma área onde houve rotação de culturas. Os genótipos foram semeados em duas épocas de plantio distintos no estado, sendo um em dezembro (17/12/2014) e outro em janeiro $(04 / 01 / 2015)$

O delineamento experimental utilizado foi de blocos casualizados, com quatro repetições e 05 genótipos de soja. Os tratamentos foram constituídos pelas cultivares TMG 1180, M9144, RAÇA, ST820, OPUS.

Os blocos experimentais de cada genótipo foram constituídos por 4 fileiras de 5 metros de comprimento, com espaço entre linhas de $50 \mathrm{~cm}$, para seleção dos grãos foram utilizadas as duas fileiras centrais, a fim de minimizar os erros recontes das plantas da borda. Antes do plantio dos grãos, o solo passou pelos processos de aração, gradagem e sulcamento, sendo que o plantio e a adubação do sulco formam feitas de forma manual, o experimento foi conduzido de acordo com os métodos técnicos primordiais a fim de mantê-lo livre da interferência de plantas daninhas, insetos e outras pragas.

As vagens de cada parcela experimental foram colhidas uma semana após apresentarem 95\% das vagens maduras, o que implica que os grãos estão no estádio $\mathrm{R}_{8}$ da escala Fehr et al., (1971). Após a colheita, as plantas foram trilhadas, e as sementes secas ao sol (obtenção de 12\% de umidade), limpas, pesadas e identificadas por cultivar.

Em seguida a colheita manual, os grãos de soja foram separados das vagens secas, triturados em moinho e procedeu-se com a metodologia de extração no Laboratório de Cinética e Modelagem de Processos (LaCiMP) do Curso de Engenharia de Alimentos da Universidade Federal do Tocantins - Campus de Palmas. A extração do óleo foi realizada com o solvente hexano em um extrator Soxhlet, sob condições de obtenção comercial de óleo (INSTITUTO ADOLFO LUTTZ, 2008). As médias foram comparadas pelo teste de Scott \& Knott, a 5\% de probabilidade.

\section{RESULTADOS E DISCUSSÃO}

A análise de variância para teor de óleo (\%) revelou efeito significativo para cultivar e épocas. Isoladamente, quando comparada cada variável estudada (cultivar e época) houve significância entre as médias comparadas na análise de variância para o teor de óleo (\%), enquanto que para interação cultivar $\mathrm{x}$ épocas não foi detectado efeito significativo, o que, fez-se necessário o desdobramento no intuito de detectar possíveis diferenças significativas entre cultivares dentro de cada época e de épocas dentro de cada cultivar.

Tabela 1. Resumo da análise de variância conjunta dos teores de óleo, em cinco cultivares de soja, semeados em Palmas-TO, na safra 2014/2015.

\begin{tabular}{ccc}
\hline \multicolumn{3}{c}{ Quadrado Médio } \\
\hline FV & GL & QM \\
Época & 4 & $8.92165^{* *}$ \\
Cultivar & 4 & $5.17084^{* *}$ \\
Cultivar x Época & 4 & $1.24092 \mathrm{~ns}$ \\
Erro & 36 & 2,98 \\
Média & & 21.44 \\
CV (\%) & & 4,45 \\
\hline
\end{tabular}

*: significativo a $5 \%$ pelo teste $\mathrm{F}$

Na primeira época de plantio (17/12/2014) (tabela 1), as cultivares que mais se destacaram foi RAÇA $(22,49 \%)$ e STS820 (21,53\%). Na segunda época de semeadura (04/01/2015) não houve diferença estatística entre as cultivares (tabela 2).

$\mathrm{Na}$ primeira época de plantio (04/01/15) (tabela 2), as cultivares que mais se destacaram foram RAÇA (22,49\%) e ST820 (21,53\%), na qual dessas a que obteve o melhor e mais alto teor de óleo foi a RAÇA (22,49\%). M9144(20,80\%) OPUS (19,88\%) e TMG1180(18,77\%) não apresentaram diferenças entre si. Na segunda época de semeadura (17/12/2014) não 
houve diferença estatística entre as cultivares (tabela 2).

Tabela 2. Teor de Óleo, em porcentagem, em sementes de 5 genótipos de soja, produzidas em duas épocas de semeadura, na safra 2014/2015 em Palmas - TO.

\begin{tabular}{cccc}
\hline \multicolumn{4}{c}{ Óleo (\%) } \\
\hline Cultivares & Época I & Época II & Média \\
TMG1180 & $\mathbf{0 4 / 1 5}$ & $\mathbf{1 7 / 1 5}$ & \\
M9144 & $20,77 \mathrm{aB}$ & $21,13 \mathrm{aA}$ & $20,45 \mathrm{~b}$ \\
RAÇA & $22,49 \mathrm{aA}$ & $21,25 \mathrm{aA}$ & $21,03 \mathrm{~b}$ \\
ST820 & $21,53 \mathrm{aA}$ & $22,35 \mathrm{aA}$ & $22,42^{\mathrm{a}}$ \\
OPUS & $19,88 \mathrm{bB}$ & $21,35 \mathrm{aA}$ & $22,44^{\mathrm{a}}$ \\
\hline
\end{tabular}

* Médias seguidas pela mesma letra minúscula, na horizontal, e maiúscula, na vertical, pertencem ao mesmo grupo pelo teste de Scott\& Knott ao nível de \% de significância.

O estudo entre as épocas de semeadura para cada cultivar, revelou similaridade de comportamento de cada um dos mesmos, com exceção de OPUS, que apresentou maior teor de óleo em semeadura mais tardia (tabela 2). Tal igualdade de comportamento dos cultivares, nas duas épocas de plantio provavelmente, ocorreu em virtude da ocorrência de baixas flutuações na temperatura (Figura 1) e precipitações (Figura 2) nos períodos de condução dos ensaios.

Figura 1. Variações de temperatura de janeiro de 2014 a maio de 2015

\section{TEMPERATURA}

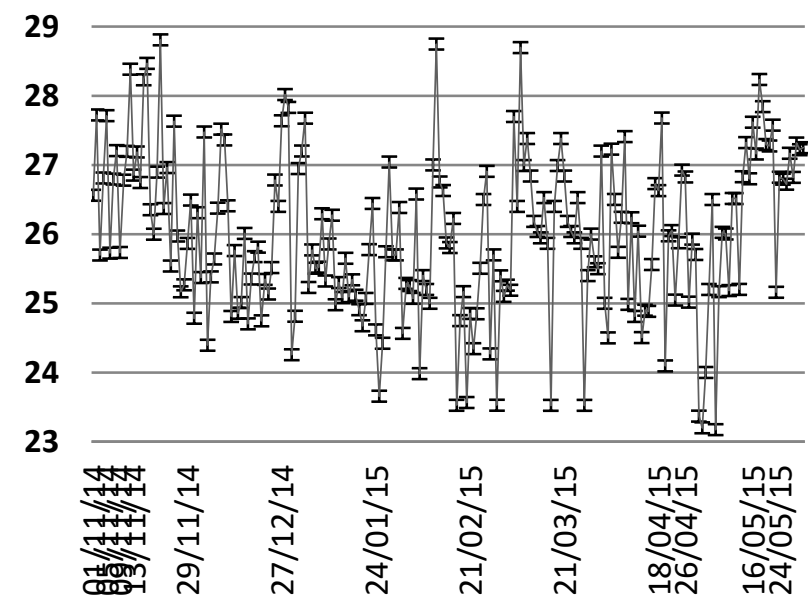

Figura 2. Precipitação entre os meses janeiro de 2014 a maio de 2015.

\section{PRECIPITAÇÃO}

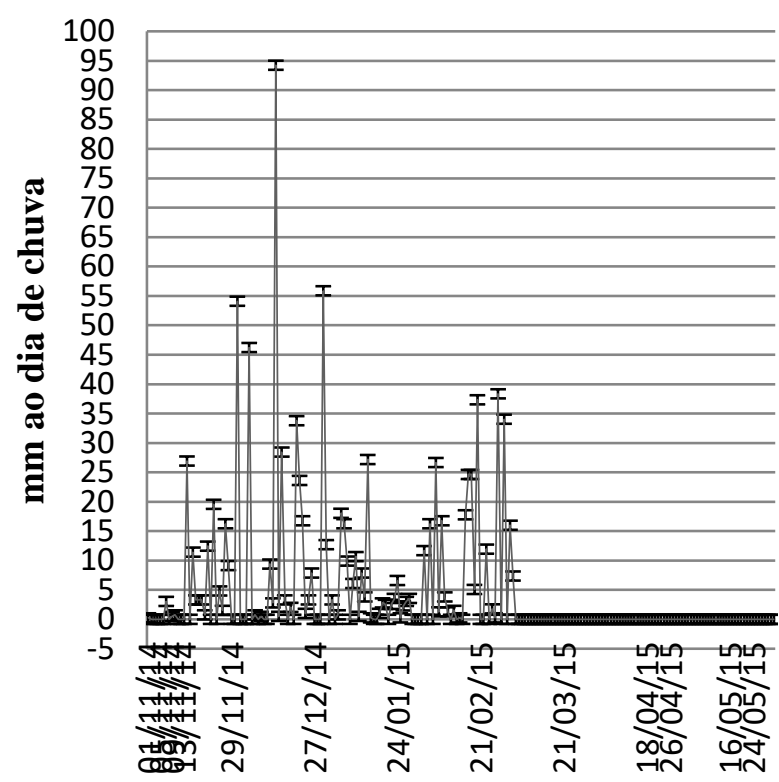

Observações semelhantes foram descritas por Lopes et al. (2011), Marcos Filho (2005), Taiz e Zeiger (2004) e Hungria et al., (2000), que afirmaram em seus estudos o efeito temperatura e precipitação na produtividade de óleo em grãos de soja cultivados em diferentes épocas de plantio.

\section{CONCLUSÃO}

De acordo com as análises pode se observar as cultivares que obtiveram um maior teor de lipídeos com possível agregação no desenvolvimento de bicombustíveis foi RAÇA $(22,49 \%)$ e ST820(21,53\%) na primeira época de semeadura. $\mathrm{Na}$ segunda data de semeadura, não foram detectadas diferenças entre as cultivares.

\section{AGRADECIMENTOS}

A toda equipe do Laboratório de Cinética e Modelagem de Processos, ao Laboratório de Pesquisa Agropecuária, ao $\mathrm{CNPq}$ pelo apoio financeiro para o desenvolvimento dessa pesquisa. 
Todos os autores declararam não haver qualquer potencial conflito de interesses referente a este artigo.

\section{REFERÊNCIAS}

CARVALHO, L. C.; BORTOLINI, J. G.; BARCELOS, A. L Biocombustíveis: uma opção para o desenvolvimento sustentável. Revista Gestão e Desenvolvimento em Contexto, v. 2, n. 2, p. 32-50, 2014.

CAVALCANTE, A. K.; SOUSA, L. B.; HAMAWAKI, O. T. Determinação e avaliação do teor de óleo em sementes de soja pelos métodos de ressonância magnética nuclear e soxhlet. Bioscience Journal, v. 27, n. 1, 2011.

DIAS, A. R.; MUCCI J. P.; AFFÉRRI, F. S. Divergência genética entre cultivares de soja, sob condições de várzea irrigada, no sul do Estado Tocantins. Revista Ciência Agronômica, v. 42, n. 1, 2011.

EMBRAPA- Empresa Brasileira de Pesquisa Agropecuária. Soja em números (safra 2012/2013). 2013. Disponível em: <http://www.cnpso.embrapa.br/index.php?cod_pai=6 9\&op_page=294 > Acesso em: 17 Fev. de 2015.

FEHR, W. R.; CAVINESS, C. E.; BURMOOD, D. T.; PENNINGTON, J. S. Stage of development descriptions for soybeans, Glycyne max L. Merril. Crop Science, v.11, p.929-931, 1971. DOI: 10.2135/cropsci1971.0011183X001100060051x.
HIRAKURI, M. H.; LAZZAROTTO, J. J. O agronegócio da soja nos contextos mundial e brasileiro. Londrina: Embrapa Soja, p. 9-15, 2014.

HUNGRIA, M.; BOHER, T. R. J. Variability of nodulation and dinitrogen fixation capacity among soybean cultivars. Biology and Fertility of Soils, v.31, p.45-52, 2000.

INSTITUTO ADOLFO LUTZ - IAL. Normas analíticas do instituto Adolfo Lutz. Métodos químicos e físicos para análise de alimentos. IAL São Paulo. São Paulo: IAL v. 1. ed IV. 2008. 317 p.

LOPES, J. A. M.; PELÚZIO, J. M.; MARTINS, G. A. S. Teor de proteína e óleo em grãos de soja, em diferentes épocas de plantio para fins industriais. Tecnol. \& Ciên. Agropec., João Pessoa, v.10, n.3, p.49-53, maio 2016.

MARCOS FILHO, J. Fisiologia de sementes de plantas cultivadas. Piracicaba: Fealq, 2005.

SBARDELOTTO, A. I. G.; LEANDRO G. V. Escolha de cultivares de soja com base na composição química dos grãos como perspectiva para maximização dos lucros nas indústrias processadoras. Ciência Rural, Santa Maria, v. 38, n. 3, p. 614-619, 2008.

TAIZ, L.; ZEIGER, E. Fisiologia do 86 estresse. Fisiologia vegetal, v. 4, p. 738-772, 2004.

VIEIRA, E. S. N.; SCHUSTER, I.; SILVA, R. B.; OLIVEIRA, M. A. R. Variabilidade genética em cultivares de soja determinada com marcadores microssatélites em gel de agarose. Pesq. agropec. bras., Brasília, v.44, n.11, p.1460-1466, nov. 2009 